\title{
Social Responsibility for Sustainable Development of Enterprise Structures
}

\author{
Vladimir Semenovich Balabanov ${ }^{1}$, Anna Vladimirovna Balabanova ${ }^{1} \&$ Mihail Nikolaevich Dudin $^{1}$ \\ ${ }^{1}$ Russian academy of Entrepreneurship, Russian Federation \\ Correspondence: Vladimir Semenovich Balabanov, Radio str., 14, Moscow, 105005, Russian Federation.
}

Received: December 15, 2014 Accepted: December 27, 2014 Online Published: March 20, 2015

doi:10.5539/ass.v11n8p111 URL: http://dx.doi.org/10.5539/ass.v11n8p111

\begin{abstract}
This article aims to study the relationship between social responsibility of business and sustainable development of enterprise structures in the current economic conditions. In the course of the research, the authors determined that: sustainable development of enterprise structures is determined by many influencing factors, localized both in the external and internal environment of an enterprise structure; sustainable development of enterprise structures cannot be achieved without the growth of business social responsibility. Social responsibility of business is integration of social and environmental problems, solved by enterprise structures in interaction with stakeholders; enterprise structures and stakeholders mutually influence each other, but this influence is not identical in strength. Sustainable development of enterprise structures depends to greater extent on influence of owners (owners of capital), competitors, public authorities; in the medium term, as the world's evolutionary problems accumulate, requirements for social responsibility of business will continue to grow. Requirements for energy efficiency management of various economic activities will play a significant role in this tendency.
\end{abstract}

Keywords: sustainable development, social responsibility, business, entrepreneurship, corporation, balanced growth

\section{Introduction}

Social responsibility of business for countries with transitive economy is a fairly new phenomenon (Dudin et al., 2013; Balabanova \& Kiseleva, 2013). Abroad, the concept of business social responsibility was introduced into business and scientific activities in the 1970s. Theoretical grounds of the concept of business social responsibility have been developed within the framework of development of business ethics as one of the key areas of applied ethics (Carroll, 2008). Initially, two theoretical assumptions were the basis of the concept of business social responsibility. The first assumption was to understand activities of enterprise structures on the basis of corporate self-interest; the second concept refers to activities of entrepreneurship and corporations on the basis of corporate altruism. Understanding the corporate egoism was down to the point that business is responsible only for growing a level of income of its shareholders by increasing efficiency of its economic activity. On the contrary, understanding the corporate altruism was down to the point that corporations and businesses are required to make significant contribution to improving a quality of life of the society, ensuring environmental safety of its activities, corporations and businesses must ensure that they promote implementation of government social programs as well (D'Amato, 2009).

Changes taking place in the global business space, revision of its social obligations by many states with its consequent reduction make small and large businesses responsible for social support not only of their employees, but also of other categories of people to a greater extent. Besides, it is already considered axiomatically that small and large businesses should be responsible for an ecological situation in the region of its presence. The concept of business social responsibility is already sufficiently developed and includes (Lee, 2008):

1) The main aspects and key issues of regulation of labour relations in the economic and territorial boundaries of corporate and enterprise structures;

2) Special programmes aimed at ensuring environmental safety of activities of corporate and enterprise structures and reducing anthropogenic impact on the environment;

3) Special programmes aimed at promoting development of the society in the region, in which these corporate and enterprise structures operate. 
On the background of globalization and integration of interests of the international business segment, it is important that not only economic but also social processes received necessary stimulus for progressive development. In this sense, business social responsibility can be considered as a basic condition of integration and coordination of interests of corporate, enterprise structures and the society (Barkov, 2004). Being in a constant and continuous relationship, business and society can interact to improve their relations comprehensively on an equal footing. At the same time, a consensus is reached between interests of capital owners to receive additional economic benefits and the public interests to preserve its normal trajectory of evolution, including through the use of performance results of corporate and enterprise structures (Kislyakova et al., 2014).

It should also be noted that sustainable development of enterprise structures, including the development based on the use of the business social responsibility concept, is a significant resource in the context of preventing possible crises of companies and enterprises performance.

The modern trends of economic globalization are such that a growing number of control actions is required to ensure sustainable development of enterprise structures (Baranenko et al., 2014; Balabanov \& Baranenko, 2008). This, in turn, means an increase in a workload level on enterprise structures management, and hence an increase in a level of management risks, associated with environment uncertainty. At the same time with an increase in the absolute level of risk and the level of load management, an important task is to ensure the quality of economic growth businesses, which in practice will be expressed in ensuring sustainable development in the medium and long term.

It is considered that an enterprise structure should always strive for sustainable development and balanced economic growth. This is the general rule for preserving viability of modern enterprises and organizations. But at different stages of the life cycle, an enterprise structure can both show outrunning growth and catch-up growth, this tendency is not characterized by balance a priori. Therefore, the balance of economic growth and sustainable development is a target and a perfect representation of the evolution of enterprise structures, which should be pursued, using the entire strategic potential, which cannot be formed without socially responsible business management (Wheeler, 2003).

\section{Methodology}

On the methodological level this article is based on the study of theoretical and practical sources on the declared subject of the article. The authors reviewed the background and progression of the concept of "business social responsibility" and have shown a correlation between the presence of social responsibility in activities of enterprise structures and their sustainable development. In addition, the authors predicted that in the medium term the concept of business social responsibility will be expanded and supplemented. In particular, we believe that business of the future is not only a socially responsible and environmentally safe activity, but it is also an energy-efficient activity of enterprise structures. So, one needs to expect a deepening of the concept of "business social responsibility" not only in order to maintain sustainable development of enterprise structures, but also in order to preserve the modern human civilization.

\section{Results}

Having appeared relatively recently, the concept of business social responsibility has come to play a key role in understanding of sustainable development of corporations and businesses. For the business sector, which is usually formed by enterprises and small and medium-sized companies, techniques, methods and approaches aimed at providing sustainable development are particularly relevant. The emerging entrepreneurial activity and the enterprise exit level out of business both in countries with transitive economies and in developed countries have roughly identical results (see Figure 1).

A difference or a differential between the emerging entrepreneurial activity and the business exit level out of business is only $0.5-0.6 \%$.

A number of scientists and scholars explain instability of modern enterprise structures with a number of traditional factors:

1) Lack of adequate or optimal state support;

2) Low competitiveness of small and medium-sized businesses if compared with large and major corporate structures;

3) Insufficient or limited access of enterprise structures to essential natural and/or financial resources;

4) Low attractiveness of small and medium-sized enterprises as employers. 
Indeed, all these factors exist and the impact of these factors on sustainable development of enterprise structures can be evaluated as extremely negative. But, on the other hand, there is also such a phenomenon as "entrepreneurial nihilism" or "entrepreneurial dependency". In the first case, as a rule, entrepreneurs, operating in the segment of small and medium-sized businesses, deny partially or ignore completely a need for compliance with legal and regulatory framework, ethical rules of conducting business. In the second case, entrepreneurs think that state structures are obliged to support all forms and direction of small and medium-sized business activities to a greater extent, including damage to the society or a large business. Both "entrepreneurial nihilism" and "entrepreneurial dependency" may be considered as negative manifestations of subjective factors influencing different kinds.

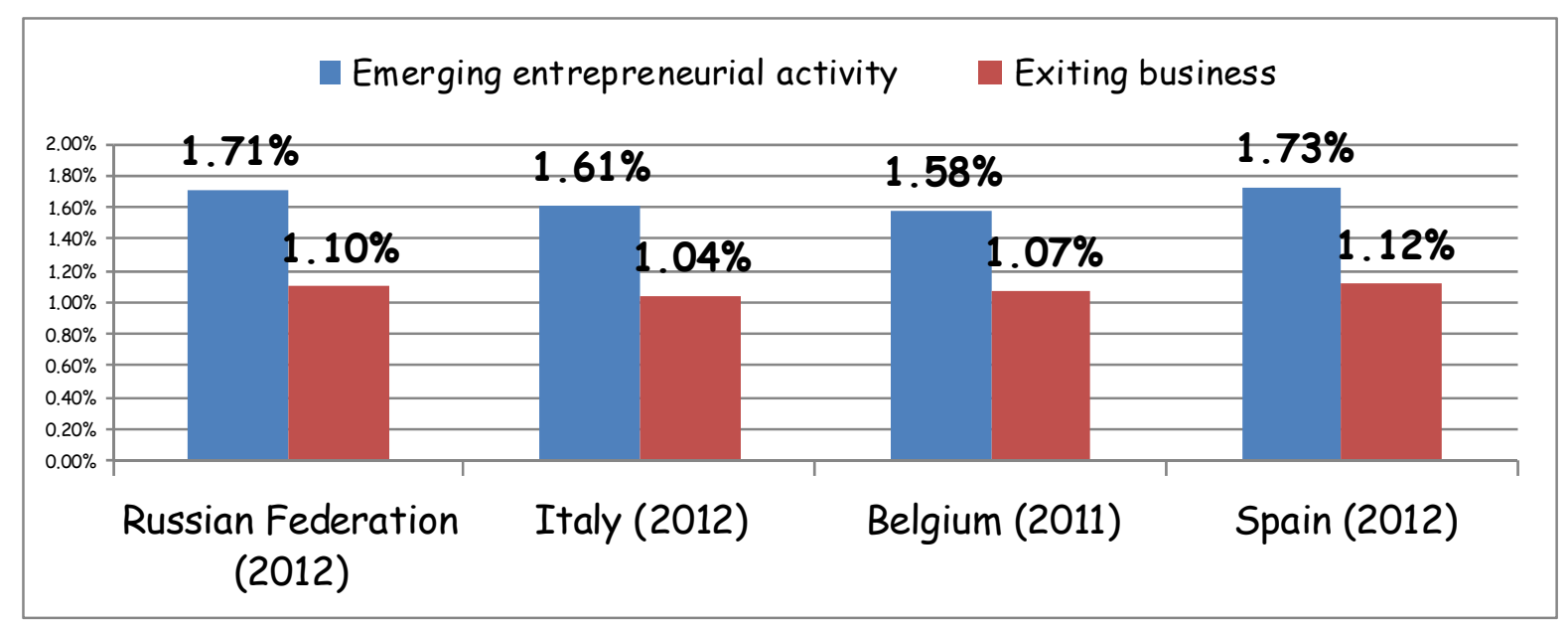

Figure 1. The level of emerging entrepreneurial activity and the exit level out of business in a number of countries (Tolstobrova et al., 2014)

Basic responsibility (only at the level of existing legislation)

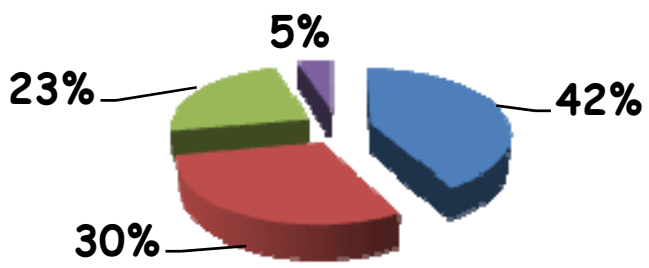

Figure 2. The structure of distributing enterprise structures at the accepted level of responsibility (Tolstobrova et al., 2014)

Existing contradictions, on the one hand, stimulate development of the business social responsibility concept, and, on the other hand, are manifested in the fact that many companies and enterprises mostly of small and medium-sized businesses understand its responsibility to the society and environment at the level of labour, ecological, tax and other legislation. This thesis is confirmed by the conducted research (see Figure 2).

It is evident that not more that $5 \%$ of enterprise structures adhere to balanced understanding of conducting business, which corresponds to the level of statistical error. In our opinion, absence of the social responsibility is one of the major reasons for the loss of stability in the development of enterprise structures.

\section{Discussion}

Modern understanding of the business social responsibility is based on the following key theoretical provisions:

1) Firstly, the business social responsibility is considered as a special concept, which at a practical level is a conscious and voluntary decision of enterprises and companies to participate in improving a life of the society and protecting the environment; 
2) Secondly, social responsibility of corporations and enterprises can be considered as integration of social and environmental problems, solved by business on the basis of its interaction with concerned parties.

Second provision seems to be more succinct, it shows that the concept of business social responsibility under examination involves two key areas: promotion of comprehensive development of socio-economic, social and labour relations, and provision of environmental safety in economic activities. In this case, interaction of enterprise structures with stakeholders takes a special place in the concept of business social responsibility. It is common knowledge that stakeholders are individuals and legal entities, from whom activity of an enterprise structure depends on directly or indirectly, and on whom this enterprise structure may have a direct or indirect impact. As a rule, stakeholders are classified into two major groups (Phillips et al., 2005):

1) Inner circle. The inner circle includes owners (owners of capital or shareholders), contractors, staff of enterprise structures;

2) Outer circle. The outer circle includes executive and legislative bodies, direct and indirect competitors, local communities, media, potential investors (lenders).

Enterprise structure can influence stakeholders or be influenced by them. Stakeholders can be distributed in eleven major groups. According to various expert estimates, enterprise structures may mostly affect its employees (staff), owners (owners of capital), business partners (contractors), customers and competitors (see Figure 3).

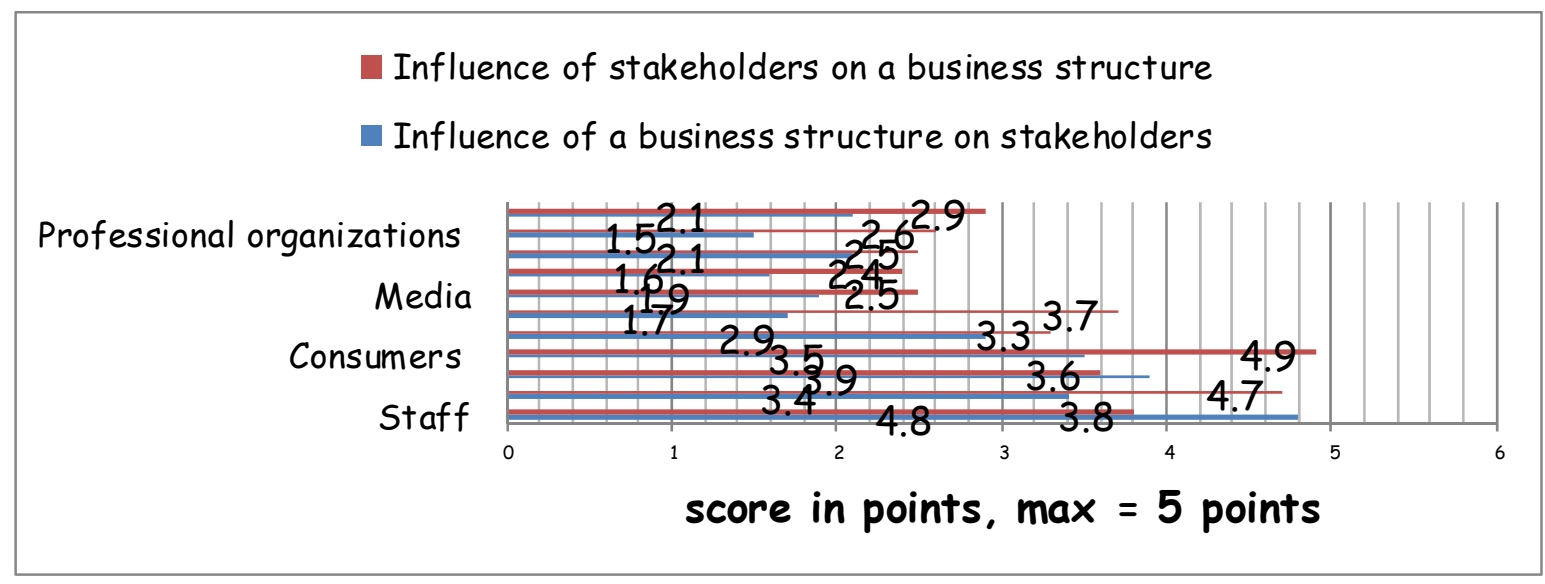

Figure 3. Expert point rating system of mutual influence of an enterprise structure and stakeholders

(Tolstobrova et al., 2014)

Owners (owners of capital), competitors (direct and indirect), contractors (business partners) and authorities have the greatest impact on an enterprise structure itself. It is obvious that influence of stakeholders and enterprise structures is mutual, but not equivalent, because in some case business has a greater impact, in other cases, stakeholders do.

The quality of interaction of an enterprise structure with stakeholders determines the quality of its social behaviour, it is important to understand that social behaviour of business entities depends on the system of values and priorities formed in the society. Each social formation and each national society formed its own system of common values and business values. It is considered that the Western model of conducting business is largely based on pragmatism and rationalism, in some cases, it borders on cynical attitude to consumers and the society as a whole. In its turn, the East Asian model of conducting business is considered to be open to a greater extent and conducting business here is largely understood as loyal towards the society and consumers.

But, at the same time, currently there are no objective arguments in support of a hypothesis of the existence of a particular business model and willingness to take the business social responsibility. Moreover, very often, western companies focus on customers; they are open and ready to contribute to social development, if compared with East Asian enterprise structures (Crowther \& Aras, 2005).

The very concept of business social responsibility has emerged as a need to reform the negativity bell in the relationships that evolved over the past decades, and the second half of the twentieth century started to be characterized by the juxtaposition of business and society. The problem is that business, exploiting national 
resources, aspired to personal enrichment of an owner (owners of capital or shareholders) to a greater extent than to creation of optimal labour conditions for its employees and provision of ecological safety of its activity.

A change of scientific paradigms in the management theory (predominance of the humanistic concept in which a key resource is the human one), as well as the growing number of environmental disasters (which allowed individual scientists and researchers to propose various apocalyptic scenarios) resulted in formation of conditions for a transition of business to conducting socially responsible activities.

By now, the business social responsibility has received regulatory and legislative consolidation in many countries, besides, major international organizations and intergovernmental structures are concerned about development of the concept of social responsibility (Hohnen, 2007). It is also worth noting that recently in the concept of the business social responsibility, charity by enterprise structures has become to play an important role.

Thus, at the present time, it is clear that business (and in particular enterprise structures) must not only pay taxes in full and on time (that is, to provide content of a national budget, including for the purposes of implementation of state social programs), but also try to increase profitability and revenues. But other than that, business should share responsibility of a state and society for promotion of social justice, economic equality and environmental safety (Hopkins, 2004). For modern enterprise structures, the implementation of the concept of social responsibility is particularly important, because, as it has been shown above, the difference between the creation of new businesses and the exit of existing market enterprise structures does not exceed $0.5-0.6 \%$.

Consequently, modern enterprise structures are not characterized by stability of its development and balanced growth. It should be noted that sustainable development of enterprise structures is not only a new scientific and practical concept, it is also an absolutely necessary condition to ensure a smooth evolution of a national and socio-economic system, and the World System as a whole. It is also indisputable that social and environmental aspects are fully integrated in the concept of sustainable development of structures and systems of the macroeconomic and the microeconomic level.

Relatively recently (at the beginning of this century) Hansen R. fairly reliably substantiated that the normal (sustainable) development of a society as a whole and, therefore, economic subjects (including business structures) depend on four types of capital (Hanson, 2007):

1) Human capital, including intellectual capital and information resources;

2) Physical capital, which is formed by means of production;

3) Natural capital, which refers to normal access to natural resources;

4) Social capital, which refers to sustainable organization of a society or a social group.

The importance of social organization sustainability is determined by Hansen R. as the highest. Consequently, enterprise structures, which are characterized by the most adaptive social architecture, have much more pronounced abilities for sustainable development and balanced economic growth. At the same time, one cannot deny importance of the environmental component of the concept of sustainable development of enterprise structures and the concept of business social responsibility. An environmental collapse and a resource crisis, which are manifested locally or globallly, cannot be excluded (Grinin \& Korotaev, 2007), but, as a rule, environmental disasters and problems of providing resources is a derivative of erroneous socio-political decisions and technological gaps that arise at different levels of macroeconomic or microeconomic management (Carroll \& Shabana, 2010).

And we would like to draw attention to one important point. Since sustainability of enterprise structures depends on availability of the above mentioned four types of capital, respectively, it is necessary that in each subsequent time the four types were structurally and dynamically proportional to growth needs of a certain economic entity. This means, for example, that lack of physical capital (including funds necessary for its formation) does not allow an enterprise structure to use the human or natural resources capital efficiently.

In turn, limited or absent access to natural resources capital reduces the value of all other forms of capital, which the enterprise structure may have or already has. Modern enterprise structures as a part of its activities constantly face problems, which may affect sustainability of development and balanced growth. Among the most important problems, it's worth singling out the following ones (Drucker, 2004):

1) Firstly, it is lack or insufficiency of resources (material, financial, human and others). Lack of resources may be due to various reasons, but the main reason is lack of funding activity at the account of its own or external sources; 
2) Secondly, it is a problem of stimulating demand and increasing product volume sales. The main reason of it is that stimulation of demand is very often based on price dumping and increase in sales volumes is based on the use of extensive approach;

3) Thirdly, it is a problem of insufficient innovative activity, as well as due to limited interaction with research institutions.

A part of the above mentioned and listed problems can be solved through introduction of socially responsible business by enterprise structures. National business associations and unions, focused on supporting business social responsibility, form codes and standards that are recommended for implementation in corporate and enterprise structures. Using these standards (social responsibility standards) in organization and conduct of business, enterprise structures have the potential to:

a) Increase a level of profitability in its activity by attracting socially responsible investments or through participation in socially oriented projects, funded by the state;

b) Increase and balance economic growth through access to new technologies of operation, designed specifically for socially responsible entrepreneurship;

c) Reduce the main part of business risks due to greening its primary (operating) activities;

d) Increase the level of competitiveness (Hamel \& Prahalad, 1990) due to revision of a strategy of long-term development of an enterprise, using the concept of the business social responsibility as a basis;

e) Provide the best enterprise structure position in the industry and create a socially responsible consumer brand.

According to scientists and researchers, the concept of business social responsibility will dominate in the upcoming century, as modern threats and challenges to human civilization as a whole are the strongest and the most global. In our opinion, the concept of social responsibility will be supplemented by provisions and theses of energy-efficient business in the next 10-15 years. This is supported by global trends to optimize consumption of traditional fossil energy resources and to replace a part of energy resources consumption with renewable resources. Inefficient use of energy resources in an economy and public consumption is a key threat to sustainable development of the World System, which has been repeatedly stated at the global level (Rejder, 2000; Iyudin, 2008).

In the light of current geopolitical changes, including those related to a changing role of Asia in the global economy, consumption of energy resources will only increase. Accordingly, these factors will provoke social unrest (due to limited availability of these resources) and environmental problems, as a set of political, social, economic and technological impact on the World System. Hence we can say that socially responsible, environmentally friendly, energy-efficient business is a business of enterprise structures, which will operate under conditions of a cognitive economy of the information society.

\section{Conclusion}

The importance of social responsibility for sustainable development of enterprise structures becomes more and more significant. We can say that the social responsibility of business is a key factor that enables an enterprise structure, on the one hand, to carry out a relatively crisis-free (and, hence, sustainable) development in order to ensure interests of owners, on the other hand, contribute to a normal evolution of the society and the national economy due to taking certain liabilities. These obligations can be expressed in terms of facilitating and promoting the optimal social and working relationships and through provision of ecological safety in economic activities.

Until relatively recently (in the second half of the twentieth century), the business social responsibility was based on good will and personal altruism of entrepreneurs. At present, the business social responsibility is an integral part and a strategic platform for sustainable development of enterprise structures. Desire of the corporate segment and the business segment to conduct socially responsible business, on the one hand, is due to the ever-increasing global and national legal requirements, on the other hand, due to rational motivation of entrepreneurs themselves, based on understanding and awareness of global threats and challenges to humanity. Certainly, development of enterprise structures, based on the concept of business social responsibility, not only promotes preservation of stability and balanced economic growth (through receiving additional economic benefits as well). Well, in addition, the use of the concept of business social responsibility provides a number of undeniable competitive advantages. The following advantages are worth mentioning:

1) Improvement of an image and public perception of companies and enterprises;

2) Improvement of a quality of interaction with target audiences, stakeholders; 
3) Updating inter-company and other cooperation ties.

In our opinion, in the short-term term perspective, the concept of business social responsibility will be expanded and supplemented by provisions of energy efficiency, since problems of energy consumption, impact of extraction of these resources on the society and the environment are the most serious. Social and environmental disasters, related to irrational distribution and consumption of energy resources, have a fairly high probability. Therefore, we believe that sustainable development of enterprise structures will be achieved through business social responsibility and its environmental safety in energy efficiency.

This paper did not address methodical and methodological issues of measuring and assessing quality of business social responsibility of enterprise structures. Given methods of assessing a level and quality of business, social responsibility is a separate and quite a capacious topic of scientific research, the authors plan to disclose these issues in their future articles and papers. The authors also plan that in the long term further studies will be focused on components of the concept of "social responsibility" and the role of energy efficient business in the framework of this concept will be determined.

\section{References}

Balabanov, V., \& Baranenko, S. (2008). Reasons and methods of counteracting the loss of stability of the organization. Guide for entrepreneurs, 1, 7-21.

Balabanova, A., \& Kiseleva, O. (2013). Middle class and its key role in development of civilized market relations. Scientific notes of the Russian Academy of Entrepreneurship, 35, 16-27.

Baranenko, S., Dudin, M., Ljasnikov, N., \& Busygin, K. (2014). Using environmental approach to innovation-oriented development of industrial enterprises. American Journal of Applied Sciences, 2(11), 189-194. http://dx.doi.org/10.3844/ajassp.2014.189.194

Barkov, S. (2004). Sociology of organizations. Moscow: Publishing House of the Moscow State University.

Carroll, A. (2008). In A. Cran, A. McWilliams, D. Matten, J. Moon, \& D. Siegel (Eds.), A history of corporate social responsibility: Concepts and practices. The Oxford Handbook of Corporate Social Responsibility. Oxford: Oxford University Press.

Carroll, A., \& Shabana, K. (2010). The Business Case for Corporate Social Responsibility: A Review of Concepts, Research and Practice. International Journal of Management Reviews, 85-105. http://dx.doi.org/ 10.1111/j.1468-2370.2009.00275.x

Crowther, D., \& Aras, G. (2005). Corporate Social Responsibility. Ventus Publishing ApS.

D'Amato, A., Henderson, S., \& Florence, S. (2009). Corporate Social Responsibility and Sustainable Business. Greensboro, North Carolina: Center for Creative Leadership.

Drucker, P. (2004). Encyclopedia of management. Moscow: Williams.

Dudin, M., Ljasnikov, N., Kuznecov, A., \& Fedorova, I. (2013). Innovative transformation and transformational potential of socio-economic systems. Middle East Journal of Scientific Research, 10(17), 1434-1437. Retrieved December 24, 2014, from http://www.idosi.org/mejsr/mejsr17(10)13/8.pdf

Grinin, L., \& Korotaev, A. (2007). Social macro-evolution and historical process. Philosophy and Society, 2, 19-67.

Hamel, G., \& Prahalad, C. (1990). The Core Competence of the Corporation. Harvard Business Review, 16.

Hanson, R. (2007). Catastrophe, Social Collapse, and Human Extinction. Global catastrophic risks.

Hohnen, P. (2007). Corporate Social Responsibility: An Implementation Guide for Business. International Institute for Sustainable Development.

Hopkins, M. (2004, May). Corporate social responsibility: An issues paper. International Labour Organization. Working Paper, 27, 41.

Iyudina, E. (2008). Influence of environmental factors on competitiveness of enterprises. Herald of the Institute of Economics, 3, 102-118.

Kislyakova, Y., Grahova, E., \& Anisimova, N. (2014). Development of the principles of production management through corporate social responsibility and sustainability of the organization. Economics and Entrepreneurship, 5(1), 783-786.

Lee, M. (2008). A review of the theories of corporate social responsibility: Its evolutionary path and the road 
ahead. International Journal of Management Reviews, 10, 53-73. http://dx.doi.org/10.1111/j.1468-2370. 2007.00226.x

Phillips, R., Freeman, R., \& Wicks, A. (2005). What stakeholder theory is not? Business Ethics Quarterly, 13, 479-502. http://dx.doi.org/10.5840/beq200313434

Rejder, J. (2000). Regulation of monetary streams in developing firms. Management Hand Book (II), 13-24.

Tolstobrova, N., Osipova, M., \& Simagutin, T. (2014). Corporate social responsibility as a factor of sustainable development of socio-economic systems at different levels. Management of economic systems: Electronic scientific journal, 4(64), 37-40.

Wheeler, C., Colbert, B., \& Freeman, R. (2003). Focusing on value: reconciling corporate social responsibility, sustainability and a stakeholder approach in a network world. Journal of General Management, 28(3), 1-28.

\section{Copyrights}

Copyright for this article is retained by the author(s), with first publication rights granted to the journal.

This is an open-access article distributed under the terms and conditions of the Creative Commons Attribution license (http://creativecommons.org/licenses/by/3.0/). 